\title{
Entrevista: Marcio Pochmann
}

\begin{abstract}
Marcio Pochmann está à frente da Secretaria do Desenvolvimento, Trabalho e Solidariedade (SDTS) da Prefeitura de São Paulo, gestão de Marta Suplicy. Livre-docente do Departamento de História e Política Econômica do Instituto de Economia da Unicamp, atuou até 2001 no Centro de Estudos Sindicais e de Economia do Trabalho (Cesit), quando licenciou-se para assumir o cargo de secretário. Nesta entrevista, realizada em 29 de setembro de 2004, ele apresenta os detalhes da estratégia de inclusão social constituída pela secretaria.
\end{abstract}

Fábio de Oliveira - Comecemos pela sua trajetória. Sabemos que você trabalhou com o movimento sindical e teve uma passagem pelo Dieese, antes de chegar à Unicamp. Como foi esse caminho?

Marcio Pochmann - Então, eu sou gaúcho do interior do Rio Grande do Sul, de uma cidade chamada Venâncio Aires. Uma cidade de colonização alemã, inclusive. Eu tive inicialmente uma experiência no movimento estudantil, cheguei a ser presidente do grêmio literário lá da minha escola, no ensino médio, depois eu estudei na Universidade Federal do Rio Grande do Sul e lá também tive uma experiência na militância estudantil: cheguei a ser presidente do diretório acadêmico da administração, economia, contábeis etc. E, posteriormente, fui contratado como auxiliar técnico do Dieese no Rio Grande do Sul. Trabalhei um ano lá, em 1984. Depois, de 1985 a 1988, eu fui o responsável técnico pelo escritório regional do Dieese em Brasília. Foi uma época muito legal, já que se tratava da conclusão da transição democrática no Brasil. Época da Constituinte, das tentativas de pacto social, quase o período ainda da hiperinflação, da organização do sindicalismo do ponto de vista das centrais sindicais em Brasília. Foi uma experiência muito interessante.

Em 1989, eu me desloquei de Brasília para a cidade de Campinas, onde passei a fazer parte do grupo de pesquisadores vinculados ao Cesit, o Centro de Estudos Sindicais e de Economia do Trabalho, no Instituto de Economia da Universidade Estadual de Campinas. Onde, além de me aprofundar no âmbito das pesquisas, eu terminei fazendo também o doutorado em economia. Fiquei um ano e meio fora do Brasil fazendo uma pesquisa para o meu doutoramento. Estive na Itália, na França e na Inglaterra. Eu defendi a tese de doutorado em 1993, continuei na Unicamp como professor, fiz o concurso de livre-docência em 2000. Eu segui a carreira acadêmica, basicamente é isso, como professor, pesquisador.

Em 2001, vim aqui para São Paulo para ajudar a construir uma estratégia do que chamamos de inclusão social, o que passou pela constituição da Secretaria do Desenvolvimento, Trabalho e Solidariedade (SDTS) e desses nove programas que estão em operação de lá para cá.

Fábio - Como foi essa passagem de alguém que assessorou o movimento sindical, que entra para a academia, faz sua carreira lá dentro e em um certo momento vem para o poder público ocupar um cargo executivo?

Marcio - No fundo, eu diria que tinha um interesse de ter uma experiência em uma função executiva. Eu já tinha tido algumas ofertas, uns seis convites para participar, em situações distintas, em diferentes esferas de governo, mas nunca me senti suficientemente estimulado 
para participar. Com a Marta, ela me convidou argumentando justamente sobre esse enorme desafio que seria constituir alguma coisa diferente, que visasse fundamentalmente a romper com a tradição das políticas sociais. Então eu me senti atraído e desafiado.

Fábio - E não havia uma Secretaria do Trabalho antes no município, não é?

Marcio - Isso, não tinha nada. Lamentavelmente.

Fábio - Sim, lamentavelmente.

Marcio - Então... mas, ao mesmo tempo, eu me achei muito voluntarioso, digamos assim. Porque, em primeiro lugar, eu não tinha nenhuma experiência no poder executivo, iríamos assumir uma Secretaria que não tinha estrutura, não tínhamos orçamento, não tínhamos corpo funcional e estávamos em uma cidade como São Paulo, com a escala de tudo o que acontece aqui. Por outro lado, haveria também um certo questionamento em que medida um acadêmico teria condições de tirar do papel algumas das propostas que a própria prefeita havia defendido em sua primeira campanha, que eram quatro programas sociais. Foram momentos muito complexos nesse primeiro ano, que foi justamente um ano chave porque representou a constituição de um desenho da estratégia de inclusão social. E de tudo o que decorreu disso: fazer projetos de leis sobre a Secretaria, sobre cada um dos programas, definir a operacionalização dos programas, que vai desde a identificação de fontes orçamentárias para financiá-los, identificar parceiros, definir quais seriam as etapas, a simultaneidade e a integração de cada uma das três fases de nossa estratégia: uma coisa é beneficiar as pessoas com garantia de renda, outra coisa é um choque de emancipação e o terceiro ponto é o apoio ao desenvolvimento local. Realizar todas essas coisas simultaneamente foi realmente muito difícil. Não tínhamos essa experiência e não tínhamos a quem recorrer, pois não existia na época um livro ou alguém que já tivesse feito isso em algum lugar, em alguma cidade ou em algum país. E, por outro lado, quero reconhecer, a Marta nos deu total liberdade para poder fazer tudo da maneira que achássemos necessário: esta Secretaria sempre foi, eu costumo dizer assim, "técnica", pois não existiu nenhuma pressão em nome da governabilidade ou algo parecido. Nós tivemos total liberdade. Claro que conversando com a prefeita, evidentemente, mas total liberdade para implantar essa estratégia, que contou sempre com o apoio da prefeita. Por isso, tivemos condições bastante favoráveis nesse sentido. Tivemos também a sorte de constituir uma secretaria com um corpo funcional relativamente pequeno, mas com excelente capacidade técnica, de intervenção e, ao mesmo tempo, a vontade de engajar-se na transformação da realidade da cidade de São Paulo.

Conseguimos, na verdade, trazer gente de várias universidades paulistas, Unicamp, USP, Unesp, Fundação Getúlio Vargas, universidade privadas, o que permitiu esse salto de qualidade. Talvez esta seja a Secretaria com o maior nível de escolaridade em termos per capta do município, com mestrandos, mestres, doutores etc. Esses dias, por exemplo, participei da banca de uma tese feita sobre a Secretaria na área de filosofia da USP. Acho que já há umas cinco teses sobre o assunto.

Fábio - Das parcerias que estabelecemos com vocês, tanto pelo Instituto de Psicologia da USP, quanto pela Faculdade de Psicolgia da PUC-SP, acredito que em breve também teremos publicações analisando as políticas implementadas pela SDTS. 
Marcio - Que bom! Na verdade, não é muito comum ter muitos indicadores de avaliação, seja de programas, seja de secretarias ou ministérios; não é da tradição brasileira. Mas o que estamos observando na SDTS é o contrário: a difusão de conhecimento tem sido muito intensa, o que para mim é extremamente estimulante.

Fábio - A avaliação de políticas públicas não é um tradição entre nós...

Marcio - Lamentavelmente!

Fábio - Como foi essa montagem da Secretaria? Você falou de uma série de questões, de coisas a conhecer, da falta de modelos prévios. Como vocês chegaram a esse modelo de programas, de políticas?

Marcio - Eu diria que o que mais contribuiu na montagem tanto da secretaria, quanto da própria estratégia de inclusão social foi justamente a crítica que tínhamos às estruturas arcaicas de formulação de políticas e, ao mesmo tempo, a crítica contundente às tradicionais políticas sociais. A crítica que nos estimulou foi a seguinte: se não estávamos convencidos de que o que existia era suficiente - e os resultados mostravam que havia um fracasso nesse sentido -, o que seria possível constituir de forma diferente? Em primeiro lugar, estávamos e estamos convencidos de que secretarias-fim, como são as da Saúde e da Educação, por exemplo, nem tampouco secretarias-meio, como as Secretarias de Finanças e de Administração, seriam capazes de reduzir drasticamente o enorme custo-meio, o custo de operacionalização de políticas sociais. Nós sabíamos, por exemplo, que nas políticas de transferência de renda, em geral, de um terço a 50\% dos recursos estão comprometidos com as atividades de cadastramento, seleção, fiscalização, acompanhamento. Seria possível uma racionalização nesse sentido, ou seja, com menos recursos fazer melhor? Nós imaginávamos que sim. Por quê? Porque, analisando inclusive as razões que levaram o prefeito anterior a não regulamentar a lei do Renda Mínima em São Paulo. Ele dizia o seguinte: para o Renda Mínima funcionar, seria preciso contratar sete mil funcionários. Mas nós temos hoje apenas 70 funcionários e estamos atendendo 490 mil famílias, quase meio milhão de famílias atendidas, e manipulando um recurso que acumuladamente equivale a $\mathrm{R} \$ 1$ bilhão. Como foi possível fazer isso? Na verdade, tratou-se de constituir um novo padrão de gestão. Em que medida isso se operacionalizou? A idéia foi constituir uma Secretaria de projetos, uma secretaria de articulação, capaz de articular a área social (Educação, Saúde, Transporte, etc.). Então, de início, nós constituímos um fórum, um conselho intersecretarial que reuniu 11 secretarias e cinco empresas públicas envolvidas com a estratégia de inclusão social. Isso nos permitiu, entre outras coisas, reduzir custos. Hoje o custo-meio da Secretaria está em torno de 7\%, isto é, de todos os recursos da Secretaria, nós gastamos 7\% com os custos de operacionalização. $\mathrm{O}$ restante dos gastos são com os programas de redistribuição de renda, de capacitação e assim por diante. A tradição no Brasil é de se gastar entre $1 / 3$ e $50 \%$ dos recursos com o custo-meio. Superar essa tradição foi possível porque fizemos um trabalho articulado com a Educação, com a Saúde, fizemos um cadastramento único para todos os programas, ao contrário da tradição brasileira, que é ter um cadastro para cada programa. E compartilhamos beneficiários com a Educação, com a Saúde, com os programas federais (como o Bolsa-Família), com os programas estaduais (como o Renda Cidadã). Para todos, um só cadastro. Assim, nós ganhamos agilidade.

Outro aspecto: por ser uma Secretaria de articulação, isso nos permitiu romper com a 
lógica de concorrência que existe entre as esferas de governo. São Paulo é a única cidade que tem os programas de transferência de renda integrados nos planos municipal, estadual e federal. Com essa estratégia, não há sobreposição de ações e podemos complementar valores menores oferecidos pelos outros níveis de governo. Isso nos permitiu fazer uma boa aliança com governos de diferentes esferas e de diferentes partidos. E nos deu um grande reconhecimento.

Então, é isso: conseguimos fazer de modo diferente a gestão e, ao mesmo tempo, nós conseguimos apresentar escala nas ações. Quando viemos para a Secretaria, o orçamento que tínhamos para 2001 (aprovado em 2000) era de R \$ 3,1 milhões. Mas nós chegamos a gastar $\mathrm{R} \$ 68$ milhões no primeiro ano e estamos gastando em torno de $\mathrm{R} \$ 250$ milhões por ano. $\mathrm{Ou}$ seja, nós gastamos entre 2,5\% e 3\% do orçamento da cidade de São Paulo com essa estratégia. Houve um espaço significativo em termos de recursos. Nós não fazemos programas em pequena escala, fazemos programas de grande escala.

E, ao mesmo tempo, isso aponta para uma situação inovadora: na verdade, nós estamos preocupados não é com que as pessoas entrem nos programas, estamos preocupados com que as pessoas saiam dos programas, o que é justamente a perspectiva da emancipação, que nós dividimos em três dimensões: emancipação social, política e econômica.

O trabalho voltado para a emancipação social começou com a definição das regiões prioritárias para o início da implantação dos programas, tendo como base os sete critérios de emancipação social. São sete indicadores: pobreza, violência, desemprego, desigualdade de renda, analfabetismo, escolaridade, proporção da presença de crianças e de adolescentes no total da população. Esses dados permitiram fazer um ranking da exclusão social nos 96 distritos da cidade. Isso nos tirou, de um lado, a pressão partidária para a escolha dos distritos.

Fábio - Vocês tinham um argumento técnico...

Marcio - Sim, tínhamos e temos. Isso nos permitiu fazer um amplo cadastramento e sairmos da modalidade tradicional que é de operar políticas sociais por meio de cotas, ou seja, por exemplo, fornecer cotas de cestas básicas para instituições distribuírem benefícios para os seus próprios cadastrados. Ao contrário, nós fizemos um cadastramento voluntário e único, estimulado por uma boa divulgação dos programas. As pessoas se inscreviam e, cumpridos os requisitos, passavam a ter acesso aos programas. Então, nesse sentido, são programas de características universais. Da população pobre, que dimensionamos com base no senso demográfico de 2000, atendemos oito em cada dez pessoas em 2004. Mais de 400 mil famílias, o que dá um total de 2,2 milhões de munícipes atendidos. Praticamente $20 \%$ da população da cidade de São Paulo foi direta ou indiretamente afetada por programas desse tipo.

Fábio - É 80\% da população que está abaixo da linha de pobreza.

Marcio - Exatamente. Talvez hoje a maior experiência desse tipo no mundo seja esta que está acontecendo em São Paulo. E nós valorizamos o que? Valorizamos a emancipação social. O que é emancipação social? Bem, como fruto das políticas neoliberais, inclusive das formas de se olhar à pobreza, identifica-se o pobre como um fracassado, como a pessoa que foi ela mesma incapaz de ter acesso ao emprego, seja porque não estudou, seja porque fracassou ao longo da vida. Influenciada por tais idéias essa pessoa, em geral, não tem sua emancipação social, em parte, porque ela não acredita em si mesma. Então, a primeira etapa dos nossos 
programas é buscar a emancipação social: conseguir com que as pessoas possam se identificar como capazes de reconstituírem a sua própria vida, de transformarem a sua realidade. Essa etapa é feita durante dois meses com um módulo cujo conteúdo são discussões sobre ética, cidadania, direitos, deveres, política, economia, que questiona por que há desemprego, quais suas razões, que não é um problema individual, mas um problema da coletividade etc.

A segunda dimensão da emancipação é a emancipação política: as pessoas que participam dos programas não são aquelas pessoas que só entraram porque votam ou votarão na prefeita ou no político de plantão. Nós objetivamos a participação, a cidadania plena em que a decisão do voto é uma conseqüência do estágio de cidadania em que a pessoa se encontra. Ela tem a liberdade de votar em quem ela quiser e isso não vai afetar, em nenhum momento, a sua participação nos programas! O que nós observamos é que, na medida em que as pessoas participam dos nossos programas - que são, no fundo, programas de empoderamento -, as pessoas ficam muito mais críticas! Ao contrário daquela passividade de achar que "o programa foi ótimo", as pessoas fazem críticas. Muitos achariam que isso é uma coisa negativa, pois, em geral, qualquer gestor público, qualquer político quer ser sempre elogiado. Mas eu identifico o contrário, pois quanto mais críticas as pessoas estiverem fazendo - se nós achamos que estamos fazendo certo e há críticas -, mais claramente se percebe que as pessoas beneficiadas elevaram seu grau de emancipação: elas reconhecem que há falhas, é claro que elas valorizam os programas, evidentemente, mas têm uma percepção crítica da sociedade. Acho que esse é o papel emulador de uma política pública.

A terceira dimensão da emancipação é a emancipação econômica: em que medida as pessoas que passam por esses programas têm condições de sair em melhores condições do que aquelas com que entraram? Essa é a parte mais difícil da fazer, pois a Prefeitura não tem a governabilidade sobre os determinantes da emancipação econômica. Isso depende do desempenho econômico do país, se há crescimento, da taxa de juros, da taxa de câmbio. Mas nós temos dado passos importantes nesse sentido. Em primeiro lugar, as articulações, as três etapas da estratégia promoveram um choque redistributivo nas regióes mais pobres da cidade com $\mathrm{R} \$ 1$ bi que foram transferidos nesses quase quatro anos de governo. Nas enquetes que fizemos com empresários e comerciantes locais, eles identificaram que houve uma melhoria no seu faturamento decorrente justamente do maior gasto das compras que as pessoas beneficiadas pelos programas sociais passaram a fazer. Houve uma maior arrecadação tributária e, por fim, houve uma expansão do emprego. Para se ter uma idéia: entre 1991 e 2000 a cidade de São Paulo perdeu 380 mil postos de trabalho. De 2001 a junho de 2004 houve uma expansão de 250 mil empregos, considerando-se apenas os com carteira assinada. Desses postos de trabalho abertos, $60 \%$ estavam na periferia. Até o ano de 2000, de cada dez empregos abertos na cidade, sete eram no centro e três, na periferia. Hoje, $60 \%$ são abertos na periferia.

Fábio - Como você consegue atribuir esse aumento do emprego à inserção de moeda, na forma das bolsas distribuídas pelos vários programas nessas regiões? Como eu posso ter a certeza dessa correlação?

Marcio - Esse indicador tem como base o Caged (Cadastro Geral de Empregados e Desempregados) do Ministério do Trabalho e do Emprego. Nós desenvolvemos uma metodologia própria para poder analisar esses dados por distritos e por bairros. O que nós observamos foi que, no passado, $70 \%$ dos empregos eram oferecidos no centro e só depois passou a ter uma predominância na periferia. Por exemplo, Itaquera é hoje uma das principais regiões geradoras de emprego. $\mathrm{O}$ que aconteceu em Itaquera? Observamos que ocorreu a expansão de negócios - sobretudo de serviços - voltados a pessoas de baixa renda. No entanto, sempre há a dificuldade de isolar o fenômeno da transferência de renda e associá-lo 
diretamente à geração de emprego, mas há indicadores, digamos, inquestionáveis que apontam para essa relação.

Um outro dado sugestivo diz respeito ao enfrentamento da polarização social entre ricos e pobres em São Paulo, cujo resultado é a própria violência. Nós temos os dados relativos aos homicídios em São Paulo: até 2000, a cada ano, aumentou o número de homicídios, chegamos a ter em 2000 quase 6 mil pessoas assassinadas em São Paulo. De 2001 para cá esse número começou a decrescer. Onde é que se observa a redução dos homicídios? Justamente nos distritos que têm os programas sociais. $\mathrm{O}$ ano de 2003 terminou com 4,9 mil pessoas assassinadas na cidade, o que ainda é um absurdo, inegavelmente. Mas é uma perspectiva diferente, pois mais de mil homicídios "deixaram" de acontecer, interrompendo, inclusive, uma tendência de crescimento que se mantinha até então.

Mas alguém vai dizer: "como é que você prova que foram os programas sociais?". Ora, eu começo a olhar os distritos e pergunto o seguinte: há alguma novidade, há mais polícia do que no ano passado, por exemplo? A novidade que está ali são os programas! Se eles não são responsáveis por $100 \%$ da variação dos índices de homicídios, uma parcela importante dessa mudança decorre desse tipo de ação pública. É claro que não estou querendo dizer que, no caso dos homicídios, a repressão não é necessária! Ela também é um componente da política social! Mas não houve uma mudança substancial em relação àquilo que havia anteriormente.

Um último exemplo é a desigualdade em termos de escolaridade e de desempenho escolar. Com os dados da própria Secretaria de Educação, nós analisamos o seguinte: comparando-se o desempenho escolar de crianças que, em 2000, estudaram na periferia de São Paulo e crianças que estudaram no centro de São Paulo no mesmo ano, observa-se que as crianças da região central tinham um desempenho três vezes maior em média do que o das crianças das regiões periféricas da cidade em termos de aprovação, repetência e abandono escolar. Três anos e meio depois, em 2003, já tendo sido implementadas as políticas de inclusão social, ao comparar-se o desempenho escolar dessas duas populações, não se encontram diferenças. A média do desempenho agora é a mesma. Logicamente houve um grande esforço na área da educação em termos de equipamentos, transporte escolar - não quero negar isso -, mas apenas quero chamar a atenção para o fato de que em um período relativamente curto de tempo é possível reduzir a desigualdade que antes estava em curso. No passado, o fato em si de estudar em uma escola de periferia - ainda que houvesse uma elevação da escolaridade - já comprometia o futuro de um jovem, pois o seu desempenho escolar, em média, seria muito menor do que o de outros que estudaram no centro ou que tiveram um nível de renda um pouco maior. Hoje, de certo modo, isso foi reduzido, porque, para criança que recebe um benefício de garantia de renda - são 480 mil crianças beneficiadas pelo Renda Mínima -, a continuidade no programa significa ter um bom desempenho escolar. E a mãe sabe disso e ela começa a se preocupar com o que está acontecendo com a criança.

Isso responde à sua pergunta? Eu acho que em parte responde. Mas na totalidade eu tenho dificuldade em precisar... como acontece no estudo de qualquer fenômeno social semelhante! E todos que trabalham com pesquisa sabem que isolar variáveis desse tipo é uma coisa realmente muito difícil.

Fábio - Em síntese, diante de todos esses exemplos que você elencou, o que cabe efetivamente a uma Secretaria Municipal fazer?

Marcio - Eu acredito que o municipalismo no Brasil é ainda muito fraco, apesar de os 
municípios terem um grau de autonomia relativamente alto. Mas a temática da questão social, do trabalho, foi sempre uma temática em relação à qual os municípios ficavam em uma posição residual e assistencialista - amparando-os "derrotados", os que "fracassaram" em suas vidas -, criando programas dos quais as pessoas ficavam dependentes, isto é, não eram programas de saída. Ou transferia-se a responsabilidade para o Governo Federal ou os Governos Estaduais...

Fábio - Que é quem, no final das contas, define as macropolíticas.

Marcio - Sem dúvida, sem dúvida... A despeito de saber disso, que os limites são muito claros, os municípios, em geral, não ocupam o espaço que poderiam vir a ocupar. Acho que a experiência de São Paulo é a que aponta justamente para esse potencial. Alguém vai dizer: "e a pobreza diminuiu?", "o desemprego caiu?", ora, sem essas políticas o desemprego seria maior, sem elas a pobreza seria maior! Há um espaço de intervenção que a municipalidade pode exercer com muito mais cuidado, mais profundidade, que é, de um lado, reconhecer que o problema existe (não dá para escondê-lo), procurar fazer um atendimento cidadão, ainda que admitindo que não se tem condições suficientes para resolvê-lo na sua totalidade, pois a solução depende de outras ações. Mas não se está abandonando esses cidadãos e tomando-os como "fracassados". Eles não são fracassados! Pelo contrário, têm um potencial enorme! E, depois de quase quatro anos lidando com esse público, eu percebo concretamente o grande potencial das pessoas. Com as várias ações que fizemos - os programas de capacitação e, depois, as experiências concretas de trabalho -, são perceptíveis os casos de pessoas que amargavam a situação de desemprego, mas, por terem passado pela experiência de uma política pública como essas, vivenciam um salto de qualidade inquestionável! Na hipótese de um crescimento econômico sustentável, essas pessoas terão a possibilidade de ingressar nessa "onda" e sair muito melhor do que estão. Agora, havendo crescimento econômico, mas sem essa passagem pelos programas, talvez essas pessoas não tivessem acesso a pegar, digamos, o "bonde" do crescimento econômico.

Fábio - E avaliando o final do ciclo deste mandato, o que você acha que é importante manter e o que faria diferente do que fez até aqui?

Marcio - Em história não existe o "se...", mas eu diria que, se fôssemos fazer de novo, muitas coisas seriam feitas de forma diferente, porque hoje temos um acúmulo, sabemos dos limites e, por isso, teríamos maior agilidade e uma ação um pouco diferente. É por isso que nós formulamos - na possibilidade de um novo mandato da prefeita - uma estratégia de inclusão social que aponta para a integração territorial. Isto é, nós já estamos no território, assim como a Saúde e a Habitação estão no território. Qual é o nosso desafio? É justamente constituir um plano combinado com um cronograma de ações integradas localmente. Então, entra saúde e família, mas entra habitação, entram os programas da nossa Secretaria, da Assistência, da Cultura e assim por diante. Ações localizadas e simultâneas. Hoje há as ações, mas elas ainda estão fragmentadas territorialmente. A idéia é, então, fazer, em um mesmo lugar, tudo de forma articulada e integrada, pois a experiência que tivemos aqui indica que os resultados assim obtidos são superiores.

Fábio - Sobre os programas de qualificação profissional oferecidos pela Prefeitura, faz sentido ter a qualificação como política que garanta emprego às pessoas, considerando que há o desemprego estrutural? Isto é, não corremos o risco de ter uma mão-de-obra qualificada e 
ainda assim desempregada?

Marcio - Bem, essa é a crítica que nós fizemos à perspectiva que foi aberta pelas experiências, digamos assim, neoliberais dos anos 90 . Em que medida nós nos diferenciamos? De duas formas. Em primeiro lugar, nós temos uma política de oferta de mão-de-obra. Isto é, uma política de educação para que as pessoas saiam do mercado de trabalho.

Fábio - Para que elas saiam ou para que elas entrem?

Marcio - Para que elas saiam. Você tem duas maneiras para resolver o desemprego. Uma, criando empregos para quem está desempregado...

Fábio - Sim, induz-se o aumento do número de postos de trabalho disponíveis...

Marcio - Sim. A outra maneira é retirar pessoas do mercado de trabalho, dando a elas condições de se prepararem melhor e para postergar o seu novo ingresso no mercado de trabalho. A Europa faz isso constantemente desde o pós-guerra. Então, qual é a nossa perspectiva? Quanto ao jovem das classes populares, o Renda Mínima e o Bolsa Trabalho são programas que têm a mesma finalidade que o ingresso tardio dos filhos das famílias de classe média e das famílias ricas no mundo do trabalho. Os filhos dessas famílias entram para o mercado de trabalho, em geral, depois de terem concluído a universidade e para ocupar os postos de direção, recebendo os melhores salários. No Brasil, os filhos dos pobres estão condenados, em geral, a começar a trabalhar muito mais cedo. E, mesmo em uma perspectiva de pleno emprego, que não é o que temos hoje, mas, mesmo assim, o que ocorreria? A continuidade dessa forma de inserção diferenciada no mercado de trabalho: os filhos dos pobres continuariam entrando no mercado de trabalho muito cedo, ocupando as vagas mais simples e de menor remuneração e os filhos dos ricos, continuariam entrando mais tarde e ocupando as vagas de direção, de tal forma que o mercado de trabalho terminaria reproduzindo a desigualdade que já é de origem. Por conta disso, o que estamos fazendo? Fazemos ações voltadas para crianças, adolescentes e jovens para que a pessoa com até 20 anos de idade e sem ter completado o ensino médio, receba uma bolsa para estudar e não entre no mercado de trabalho, isto é, para que ela saia do mercado de trabalho! Não adianta entrar no mercado de trabalho, pois não haverá emprego e a vaga que porventura essa pessoa encontrar será uma vaga de baixíssima remuneração. Essa é uma diferença: nós estamos transferindo renda, quase $3 \%$ do orçamento vai justamente para essa estratégia de saída do mercado de trabalho. É uma perspectiva diferente, por exemplo, de um programa de primeiro emprego.

$\mathrm{E}$ as pessoas que recebem essas bolsas para estudarem e qualificarem-se desenvolvem atividades comunitárias, isto é, elas oferecem um retorno à sociedade ao atuarem como cuidadores sociais, leitores, contadores de histórias, agentes comunitários de meio ambiente etc. Isto é, uma série de atividades que esses jovens realizam porque foram capacitados para tanto e que precisam realizar, juntamente com seus estudos, para ter direito ao recebimento da bolsa.

A outra ação é basicamente os programas Operação Trabalho e Começar de Novo, que envolvem uma outra estratégia, desta vez voltada para as pessoas com mais de 21 anos de 
idade. Qual é a melhor forma de preparar essas pessoas para o mercado de trabalho se não há empregos? Bem, de cada dez cursos de capacitação que fazemos, sete estão vinculados a atividades não assalariadas. Nós estamos, portanto, muito mais envolvidos com uma estratégia de formação, preparação, incubação, pós-incubação para atividades do terceiro setor, da economia solidária, pois sabemos que o emprego assalariado capitalista depende de investimentos, por exemplo, e que esse mesmo emprego vai ser ocupado por pessoas oriundas das classes média, média baixa e pelos ricos. Os pobres estão, lamentavelmente, a princípio, condenados a nem poder disputar essas vagas! Por isso é que nós temos a estratégia do microcrédito, do Oportunidade Solidária, dos programas de capacitação para o terceiro setor, pois estamos justamente preocupados em abrir um espaço para que esse público-alvo, os pauperizados, possam ter condições de gerar trabalho e renda em condições diferentes daquelas a que estariam ao disputar o emprego assalariado.

Fábio - $\mathrm{O}$ que você poderia citar como exemplo desse tipo de qualificação, além do Oportunidade Solidária, que fomenta o cooperativismo?

Marcio - Além dos programas de qualificação que preparam os indivíduos para a criação de pequenos negócios, incluindo as cooperativas do Oportunidade Solidária (que somam mais de 300 cooperativas e mais de 20 mil pessoas capacitadas nessa perspectiva de montar um pequeno empreendimento), nós temos todas as atividades dos chamados agentes comunitários, cuidadores sociais, juízes de futebol, agentes comunitários de lazer. Quem, afinal, forma pessoas para cuidar do lazer da população nas férias?

Fábio - Mas quem contrata essas pessoas?

Marcio - O setor público. Não há empresas privadas interessadas nisso. É um espaço que eu chamaria de terceiro setor, pois são atividades mercantis que não visam o lucro no sentido estrito. Mas são atividades que disputam uma renda que está aí disponível. Não é uma escola privada, por exemplo, que faz isso, são os agentes comunitários, que são contratados individualmente ou por meio de suas cooperativas. Procuramos, então, entrar nesse nicho de atividades.

Mais do que isso, no caso do São Paulo Inclui, nós fazemos intermediações. Por exemplo, um grupo monta uma cooperativa de pintores que trabalham muito bem, mas ninguém conhece ainda essa cooperativa, não há demanda. $\mathrm{O}$ que a Prefeitura pode fazer para criar e canalizar essa demanda? Nessa estratégia também entra o programa Desenvolvimento Local, que é um programa baseado em fóruns de desenvolvimento setoriais e locais nos quais a sociedade civil organizada, os beneficiados dos programas sociais e o poder público discutem e constituem uma agenda de desenvolvimento para cada localidade em termos de meio ambiente, desenvolvimento econômico, social e assim por diante. Isso representa um salto para além da discussão do orçamento participativo, por exemplo.

Fábio - E também amplia as formas de participação possíveis. Isso é muito interessante.

Marcio - Os nossos programas são muito intelectualizados, isto é, precisa-se de algum tempo para conseguirmos explicar como as coisas funcionam. Falo isso pela experiência de já ter repetido tantas vezes este relato. À medida que temos tempo para explicar, as pessoas ficam realmente impressionadas. Por outro lado, trata-se de algo desconhecido, pois poucas pessoas 
sabem que se trata de uma estratégia de inclusão social, que tem três etapas, ações redistributivas, emancipatórias, de desenvolvimento local etc., é preciso de tempo para explicar tudo e por isso é difícil criar um marketing como tem o Fome Zero, por exemplo.

Fábio - Bem, foi justamente por isso que o convidamos para esta entrevista! E devo dizer que sua equipe sempre foi muito aberta às sugestões que surgiam de nossas discussões. Para nós foi muito importante perceber o quanto podíamos influenciar as políticas públicas, pois, por muito tempo não existiu esse diálogo entre a gestão municipal e a universidade.

Marcio - Ainda sobre a dificuldade de esclarecimento dos programas, a nossa população, que lamentavelmente sempre esteve exposta a uma visão clientelista da relação com o poder público, também tem dificuldade de compreender essa nova modalidade de política pública. Muitas vezes, beneficiados do Bolsa Trabalho dizem quando ingressam no programa: "eu quero emprego, não vim aqui para assistir curso! Eu quero é arrumar um emprego!”. Depois de algum tempo mudam essa perspectiva, o que é fantástico, pois, se as pessoas têm a oportunidade de conhecer, de abrir a cabeça para pensar de maneira mais ampla, esses horizontes se modificam.

Fábio - Você citou acima o São Paulo Inclui. Por favor, fale mais um pouco sobre esse programa.

Marcio - Quando montamos a estratégia de inclusão social, pensamos em começo, meio e fim. Isto é, nossa preocuparam era a de criar condições para que as pessoas pudessem, como disse acima, sair dos programas. Nesse sentido, o São Paulo Inclui é uma das principais ferramentas, pois ele é a vinculação possível dos beneficiados dos programas com a realidade do mercado de trabalho e com as oportunidades de trabalho. Ele busca fazer a intermediação de negócios, a intermediação de trabalho e por isso o seu papel de articulação, integração e diálogo com o setores produtivos, o setor privado, o terceiro setor, com as comunidades, pois são elas que representam, na verdade, o grande potencial de geração de trabalho e renda. Ao mesmo tempo, nós observamos que muitas vezes a capacitação que estávamos oferecendo nem sempre era aquela que uma determinada empresa ou setor estavam demandando, por isso o São Paulo Inclui também cumpre o papel de afinar a formação oferecida aos beneficiados com aquilo que o mercado demanda. O que incluir, por exemplo, em um programa de formação em telemarketing ou na preparação de pessoas para trabalhar em um supermercado?

O mesmo se passa, no que se refere à articulação, com essa novidade que resultou das parcerias da Prefeitura com o Conselho Regional de Psicologia, de um lado, e com algumas universidades, de outro, que tentam potencializar as estratégias de procura por trabalho por meio de grupos de discussões com desempregados. Prática que, diga-se de passagem, distingue-se totalmente de toda a literatura de auto-ajuda que existe por aí, pois trabalhamos em uma outra perspectiva.

A nossa tentativa, considerando que o poder público pode muitas coisas, mas não pode tudo, é a de articular essa rede de instituições que já fazem com um rigor extremamente elevado determinadas ações. Nós teremos maior chance de êxito se conseguirmos combinar as ações existentes e não multiplicá-las, sobrepô-las. Essa é a perspectiva em que atua o São Paulo Inclui. 
Essa articulação envolve reaproximar da produção as pessoas que estão prisioneiras do curto prazo, tomadas pelas urgências do dia-a-dia de sobrevivência. A transferência de renda associada à capacitação permite isso.

Fábio - Nesse sentido, o trabalho que realizamos com os grupos de desempregados busca contribuir para uma apropriação realística do que acontece no mundo do trabalho hoje e, a partir disso, instrumentalizar os participantes para a construção de estratégias individuais e coletivas de sobrevivência. Os próprios programas da Prefeitura entram como parte das estratégias pessoais dos beneficiados.

O nosso grande desafio foi o de, usando dispositivos da psicologia, não cair no psicologismo, isto é, na redução do desemprego a um fenômeno apenas pessoal, mas considerando o contexto em que o fenômeno acontece e toda a astúcia que as pessoas submetidas a essas condições adversas demonstram ao construir suas estratégias de busca por trabalho e por formas de geração de renda.

Tendo em vista essas considerações, gostaria de fazer-lhe uma última questão. $\mathrm{Na}$ verdade, se você me permitir, uma pergunta provocativa. O que você sugeriria hoje para alguém que está desempregado? Qual seria o seu "conselho"?

Marcio - Bem, eu sempre tenho recusado dar esse tipo de resposta porque, em geral, o tipo de resposta que se pode oferecer é incapaz de reconhecer as dificuldades da pessoa que está desempregada. A pergunta leva a respostas genéricas, típicas do mercado da auto-ajuda. A minha primeira resposta, quando indagado dessa maneira, é que é preciso saber, antes de tudo, a situação desse alguém que está desempregado. Qual é a saída? Depende de onde a pessoa quer chegar! Há a situação emergencial da pessoa que está tão somente procurando alguma renda para sobreviver, mas também temos que reconhecer que cresceu muito o desemprego entre pessoas de maior escolaridade e uma parte importante dessas pessoas não está procurando qualquer tipo de trabalho. Assim, eu não tenho uma resposta padrão para a pergunta.

Em primeiro lugar, isto é o mais importante, deve-se reconhecer que o problema não é individual. A falha não é individual! Na maior parte das vezes é um problema coletivo e não há saídas individuais, a não ser para aqueles que, no Brasil, foram historicamente privilegiados, o que não é o caso do grande conjunto da população que hoje está desempregada. É uma não-resposta...

Fábio - Era mesmo o que imaginei que você fosse responder! Pois não é uma pergunta que, ao se tentar responder, faça-se de forma satisfatória. E você tocou no ponto mais importante que é o risco de culpabilizar o desempregado pela sua situação. Obrigado! 